\title{
Variation in the Lobar Pattern of the Right and Left lungs: A Case Report
}

\author{
Dr. Shobha $\mathbf{G}^{1}$, Dr. Jeevan Kumar Giri ${ }^{2}$, Dr. Pratikshya Majagaiyan ${ }^{3}$, \\ Dr. Manu Krishnan ${ }^{4}$, Dr. Santosh Singrapu ${ }^{5}$ \\ 2,3,4,5 PG Scholar, ${ }^{1}$ Assistant Professor \\ $1,2,4,5$ Department of Rachana Sharir, ${ }^{3}$ Department of Shalakya Tantra \\ Sri Dharmasthala Manjunatheshwara college of Ayurveda and Hospital, Hassan, Karnataka, India
}

\section{ABSTRACT}

The anatomical knowledge of the fissures and the lobes of the lung are important for accurate interpretation on CT scans. The right lung classically has two fissures, an oblique and a horizontal, dividing it into three lobes namely upper, middle and lower. Left lungs have one fissure, oblique fissure which divides it into two lobes namely upper and lower lobes. The absence of horizontal fissure in right lung and anomaly of the lobar pattern has been described by many research workers on CT scans. Whereas, there are fewer studies on gross anatomical specimens. In the present case during routine dissection in department of Anatomy, we encountered an anomalous lobar pattern of right lung; we report one horizontal and two accessory fissure dividing the right lung into 4 lobes and absence of oblique fissure in right lung. Also the presence of horizontal fissure in the left lungs dividing it into three lobes. The knowledge of anatomical variations of lung fissures is essential for clinicians, surgeons, and for radiologist to recognize various images of related abnormalities because an accessory or anomalous fissure can be mistaken for a lung lesion or an atypical appearance of pleural effusion

\section{INTRODUCTION}

The lungs are vital organs of respiratory system. It occupies the most of the pace of thoracic cavity on either side of the mediastinum. Amongst the pair, the right lung is divided into three lobes namely upper, middle and lower by oblique and horizontal fissures. The left lung is divided into two lobes namely upper and lower by oblique fissure $[1,2,3]$. The arrangement of lung tissue into lobes by fissures facilitates the movements of the lobes in relation to one another thus helping in uniform expansion of the whole lung in inspiration [4]. Behind the cardiac impression in mediastinal surface each lung shows a triangular depression named the hilum which forms the root of the lung. Both the lungs admit two pulmonary veins and one pulmonary artery through the hilum. Right hilum consist of two bronchi namely; eparterial bronchus and hyparterial bronchus. Left hilum consist of only one bronchus i.e hyparterial bronchus. [5, 6, 7].

Being vital organs of respiration, the lungs are divided by fissures into lobes which facilitate movements of lobes in relation to one another. The fissures allow for uniform expansion of lobes. They provide routes for movements of lobes in relation to each other. The appearance of accessory lung fissure varies on $\mathrm{X}$ - ray and CT scan. This is seen especially in reference to depth or completeness of the fissure. A fissure appearing complete on X-ray might be seen as an incomplete one on CT scan and vice versa may also be seen [8]. An incomplete fissure may lead to disease spread, collateral air drift and/or incomplete fissure sign. The knowledge of anatomical variations of lobes and fissures of the lung is important for identifying precise location, extent and morphology of bronchopulmonary segments. As the fissures form the boundaries for the lobes of lungs, the Knowledge of the anatomy and normal variant of the major fissures is essential for recognizing their variable imaging appearances as well as related abnormalities. Understanding of the normal anatomy is very essential foundation of the surgical knowledge, Preoperative planning and strategy for pulmonary lobectomy and segmental resection may also change during presence of such anomalous of lobar pattern and absence or presence of accessory fissures.[9] 


\section{Case Report}

During routine dissection of thoracic region of adult male cadaver in dissection hall of Department of Rachana Sharir at S.D.M. College of Ayurveda and Hospital, we encountered following variation in lobes $\&$ fissure of both lungs.

\section{The right lung}

Presence of complete oblique fissure, which normally commence from a distance of $7 \mathrm{~cm}$ from the apex of the lung on the vertebral part of the medial surface to cross the inferior border at a distance of $2 \mathrm{~cm}$ from the anterior border. It completely divide lung into two separate lobes.

$>$ Two incomplete accessory fissures are also present in the right lung which incompletely divides each lobe into 2 parts. Resulting 4 lobes in right lung. (Fig 1(A)) $>$ The hilum consists of eparterial bronchus, hyparterial bronchus, pulmonary artery \& two pulmonary veins. (Fig 2(A))

\section{The left lung}

$>$ Left lung was collapsed. The exact pathology was unknown

$>$ There were presence 2 fissures; oblique fissure and horizontal fissure which divide the left lung into three lobes (Fig. 1(B)).

$>$ The hilum consists of bronchus (hyparterial bronchus), pulmonary artery \& two pulmonary veins. (Fig 2(B))
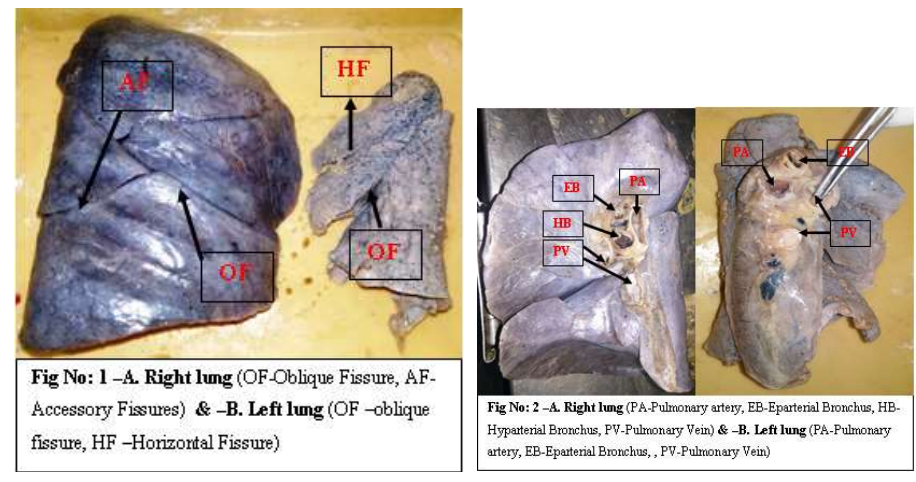

\section{Discussion}

Variations noted in lobulation and fissures in right and left lung might be as a result of altered pulmonary development. During intra-uterine life by means of lung bud which divides into a right and left bronchi bud which later forms the corresponding right and left main bronchus. The right main bronchus will give rise to three secondary bronchi for the developing three lobes of the right lung while the left main bronchus will give rise to two secondary bronchi for the two developing lobes. The secondary bronchi of both lungs divide to form the tertiary bronchi which are the primordial structures of the bronchopulmonary segments.[10] The numerous brunchopulmonary buds are initially separated by and later they fuse completely except at the sites of oblique and horizontal fissure in case right lung and at site of oblique fissure in left lung. This results in formation fissures and lobes of lungs. These fissures in the lung enable even expansion of the lung during respiration and are usually used as landmarks in specifying lesions. [11,12] The study also revealed that the presence of an accessory/variant fissure could be due to the failure of obliteration of these fissures either completely or partially. These fissures may be complete of incomplete which separates lobes of the lungs completely or partially from the main lobe of the lungs.[13]

In the present case oblique fissure and 2 accessory/variant fissures that were noted on the right lung can. Which divide the right lung into 4 lobes. This type of fissure is reported to be more common in the right lung. In the study done by Bincy M. Gerg et.al, $4.61 \%$ case show three fissure and 4 lobes in right lung.[14]. The knowledge of accessory/variant fissures is very important especially in the preoperative planning of lobectomy, radiological interpretation. Once the presence of a variant fissure is noted the procedure for a segmental resection may also have to change to avoid the post-operative complication of air leakage.[15].

In the present case left lung present with oblique and horizontal fissure with three lobes. In Bincy M. Gerg et.al, study $2.73 \%$ case show 2 fissure and 3 lobes in left lung.[16]

This present case of variations in the fissures and lobe may be the result of failure of the obliteration of the fissures either completely of partially during the development of the lungs. Accessory lobes and fissure can be misinterpreted with certain clinical condition such as linear atelectasis, pleural scars or wall of bullae on the radiological images.[17,18,19] Knowledge of this variation might be helpful to explain certain unusual X-ray presentation of the lung. Similarly, it might help to understand certain radiographic findings such as extension of fluid into a accessory/variant fissure and the spread of diseases through different pathways in the lungs.

\section{Conclusion}

Normally the right lung has two fissure i.e. horizontal fissures and oblique fissure which divides it into upper, middle and lower lobe. Similarly, the left lung has only one fissure i.e. oblique fissure which divides the lung into upper and lower lobe. Variation in the 
lobes of the lungs is due to extra fissure divides a lung. In this present case right lung has three fissures and left has two fissures that divide the lungs into four and three lobes respectively. The knowledge of variant fissures is very important especially in the preoperative planning of lobectomy. Once the presence of a variant fissure is noted the procedure for a segmental resection may also have to change to avoid the post-operative complication of air leakage. Certain radiological findings can mislead the diagnosis as in the cases of extra lobes, as it may misinterpret as lung lesions. In the presence of extra lobes, the CT scan shows a significant increase in the size of mediastinum around the trachea [20]. Similarly, it might helpful to understand certain radiographic findings such as extension of fluid into a variant fissure and the spread of diseases through different pathways in the lungs. Though, the fissures and the lobar pattern of the lungs are studied in a few populations [21]. The accessory fissure might alter usual pattern of lung collapse in patients with endobronchial lesion, and pose difficulty in diagnosing the extent of lesion. Normally pneumonia will be restricted to the lobes affected by it, but in patients with incomplete fissures, it may spread to adjacent lobes through the parenchymal continuation $[22,23]$.

\section{References}

1. Shah P, Johnson D, Standring S. Thorax. In: Standring S, editor. Gray's Anatomy: The Anatomical Basis of Clinical Practice. 39th ed. Edinburgh: Churchill Livingstone; 2005. pp. 1068-1069.

2. Keith L. Moore, Arthur F. Dalley, Anne M. R. Agur, Clinically Oriented Anatomy. $5^{\text {th }}$ ed. New Delhi: wolters Kluwer (India) Pvt. Ltd; 2009. 111-126p.

3. Chaurasia BD. B D Chaurasia's Human Anatomy Regional and Applied. 4thed. Garg DK, editor. Vol.1. Delhi: Satish Kumar Jain for CBS Publishers and Distributers; 2004. 223-230p.

4. Rosse C, Gaddum-Rosse P. Hollinshead's textbook of anatomy. Philadelphia: Lipincott Williams \& Wilkins; 1997. p. 441-461

5. Rosse C, Gaddum-Rosse P. Hollinshead's textbook of anatomy. Philadelphia: Lipincott Williams \& Wilkins; 1997. p. 441-461

6. Keith L. Moore, Arthur F. Dalley, Anne M. R. Agur, Clinically Oriented Anatomy. $5^{\text {th }}$ ed. New Delhi: wolters Kluwer(India) Pvt. Ltd; 2009. 111-126p.

7. Shah P, Johnson D, Standring S. Thorax. In: Standring S, editor. Gray's Anatomy: The Anatomical Basis of
Clinical Practice. 39th ed. Edinburgh: Churchill Livingstone; 2005. p. 1068-1069.

8. Shah P, Johnson D, Standring S. Thorax. In: Standring S, editor. Gray's Anatomy: The Anatomical Basis of Clinical Practice. 39th ed. Edinburgh: Churchill Livingstone; 2005. pp. 1068-1069

9. Brahmbhatt RJ, Chauhan KB, Bansal M, Brahmbhatt JN. Cadaveric study of azygous lobe of lung. Int $\mathrm{J}$ Basic Appl Med Sci. 2013; 3:30-33.

10. Datta A.K, Essential of Human Embryology, $5^{\text {th }}$ ed. 2005, Calcutta; Current Book International, 155-156p.

11. Larsen WJ. Human embryology. New York: Churchill Livingstone; 1993. pp. 111-130.

12. Datta A.K, Essential of Human Embryology, $5^{\text {th }}$ ed. 2005, Calcutta; Current Book International, 155-156p.

13. Meenakshi S, Manjunath KY, Balasubramanyam V. Morphological variations of the lung fissures and lobes. Indian J Chest Dis Allied Sci. 2004; 46:179182. [Pub Med]

14. Bincy M. George, Satheesh B. Nayak \& Sapna Marpalli: Morphological Variation of the Lungs: A study Conducted on Indian Cadavers. Anatomy and Cell biology journal. 2014; 47(4): 253-258. [Pub Med]

15. Tarver RD. How common are incomplete pulmonary fissures, and what is their clinical significance? AJR AmJ Roentgenol. 1995; 164:761. [Pub Med]

16. Bincy M. George, Satheesh B. Nayak \& Sapna Marpalli: Morphological Variation of the Lungs: A study Conducted on Indian Cadavers. Anatomy and Cell biology journal. 2014; 47(4): 253-258. [Pub Med]

17. Brahmbhatt RJ, Chauhan KB, Bansal M, Brahmbhatt JN. Cadaveric study of azygous lobe of lung. Int $\mathrm{J}$ Basic Appl Med Sci. 2013; 3:30-33.

18. Larsen WJ. Human embryology. New York: Churchill Livingstone; 1993. pp. 111-130.

19. Bincy M. George, Satheesh B. Nayak \& Sapna Marpalli: Morphological Variation of the Lungs: A study Conducted on Indian Cadavers. Anatomy and Cell biology journal. 2014; 47(4): 253-258. [Pub Med]

20. Speckman JM, Gamsu G, Webb WR. Alterations in CT mediastinal anatomy produced by an azygos lobe. AJR Am J Roentgenol. 1981; 137:47-50. [Pub Med]

21. Brahmbhatt RJ, Chauhan KB, Bansal M, Brahmbhatt JN. Cadaveric study of azygous lobe of lung. Int $\mathrm{J}$ Basic Appl Med Sci. 2013; 3:30-33.

22. Aldur MM, Denk CC, Celik HH, Tasçioglu AB. An accessory fissure in the lower lobe of the right lung. Morphologie. 1997; 81:5-7. [Pub Med]

23. Tarver RD. How common are incomplete pulmonary fissures, and what is their clinical significance? AJR Am J Roentgenol. 1995; 164:761. [Pub Med] 